\title{
Exploiting gas diffusion for non-invasive sampling in flow analysis: determination of ethanol in alcoholic beverages
}

\author{
Simone ViCENTE, Elias A.G. ZAGATTO, PAUla C.A.G. PINTO*, \\ MARIA LUCIA M.E.S. SARAIVA*, JOSÉ L.F.C. LIMA* and EDUARDO P. BORGES \\ Centro de Energia Nuclear na Agricultura, Universidade de São Paulo, \\ Av. Centenário 303, 13416-000 Piracicaba, SP, Brasil \\ Manuscript received on February 25, 2005; accepted for publication on September 27, 2005; \\ contributed by EliAS A. G. ZAGATTO**
}

\begin{abstract}
A tubular gas diffusion PTFE membrane is exploited for non-invasive sampling in flow analysis, aiming to develop an improved spectrophotometric determination of ethanol in alcoholic beverages. The probe is immersed into the sample, allowing ethanol to diffuse through the membrane. It is collected into the acceptor stream (acidic dichromate solution), leading to formation of $\mathrm{Cr}(\mathrm{III})$, monitored at $600 \mathrm{~nm}$. The analytical curve is linear up to $50 \%$ (v/v) ethanol, baseline drift is $<0.005$ absorbance during four working-hours, and sample throughput is $30 \mathrm{~h}^{-1}$, meaning $0.6 \mathrm{mmol} \mathrm{K}_{2} \mathrm{Cr}_{2} \mathrm{O}_{7}$ per determination. Results are precise (r.s.d. $<2 \%$ ) and in agreement with an official procedure.
\end{abstract}

Key words: Flow-injection analysis, ethanol determination, gas diffusion, semi-permeable membrane, UVVis spectrophotometry.

\section{INTRODUCTION}

Flow Analysis is an approach to automated analytical chemistry relying on handling of aqueous samples inside narrow-bored tubing. It can be considered as the art of playing analytical chemistry in flowing streams. The involved solutions are managed inside an environmental-protected system under reproducible conditions, allowing the required steps inherent to the analytical protocol to be efficiently performed. Earlier applications demonstrated the beneficial aspects inherent to the reduced intervention of the analyst (Hartridge and Roughton

*Present address: REQUIMTE, Departamento de QuímicaFísica, Faculdade de Farmácia, Universidade do Porto, Rua Aníbal Cunha 164, 4050-047 Porto, Portugal

**Member, Academia Brasileira de Ciências

Correspondence to: Elias A.G. Zagatto

E-mail: ezagatto@cena.usp.br
1923), and other advantages have been often emphasized (Trojanowicz 2000, Zagatto and Worsfold 2005).

The first overall accepted flow analyzer was based on the concept of Air-Segmented Continuous Flow Analysis (Skeggs 1957) and played a relevant role in the field of automated analysis especially in relation to large-scale clinical assays. Its exploitation led to a pronounced reduction of analyst labor, reagent consumption, and waste generation (Ruzicka and Hansen 1988). Additional advantages can be attained by injecting the sample into a nonsegmented flowing stream, and this led to the inception of Flow Injection Analysis, FIA (Ruzicka and Hansen 1975). High sample throughput (typically 30 to $220 \mathrm{~h}^{-1}$ ), high versatility and precise sample handling are inherent to the FIA system (Tro- 
janowicz 2000). In view of its beauty of simplicity, FIA systems have been worldwide accepted as an analytical tool, as demonstrated by the number and quality of proposed applications, books, academic theses and available commercial analyzers (Trojanowicz 2000, Smith and Hinson-Smith 2002, Ukeda 2004).

FIA systems exploiting gas diffusion for in line analyte separation are worthwhile for improving selectivity, and largely used for analysis of biological fluids, fermentation media and other complex matrices (Fang 1993). An important feature is that the diffusion process is reproducible but not necessarily needs to reach completion (Zagatto et al. 1979), thus speeding up the analytical cycle without hindering accuracy. They usually comprise a donor and an acceptor stream separated from each other by a semi-permeable barrier (or an air gap) that allows the selective mass transfer. This barrier is generally a flat semi-permeable membrane (Miro and Frenzel 2004), although tubular membranes have been also used. In this later situation, a concentric geometry is established with the membrane tube set inside another conventional tube (plastic or metal). In this way, the donor and acceptor streams flow one inside and the other outside the membrane, and this feature is useful for designing sampling-probes (Rothfuss et al. 1996).

The determination of ethanol is very important for the fermentation process control and for legal beverage specification (Jacques et al. 2003). An official procedure (Cunniff 1995) is based on evaluation of the specific mass of the sample distillation products. Although accurate and precise, it is time-consuming and requires a large sample amount. Chromatographic (Callul et al. 1992) and enzymatic-based (Schmid 1991, Fernandez and Reis 2004) procedures can also be applied. Another possibility is the simple and rugged spectrophotometric method involving $\mathrm{Cr}(\mathrm{VI})$ reduction by ethanol (Caputi et al. 1968). For improving selectivity however a distillation step is necessary. This drawback was circumvented by Mattos et al. (1998) who designed a FIA system with in line gas diffusion for ethanol determination in wines and distilled spirits. The flow system was however somewhat complex.

This paper reports the use of a gas-diffusion probe as a non-invasive sampling device in flow injection analysis, in order to simplify the abovementioned procedure. A simple and rugged FIA system for spectrophotometric determination of ethanol in alcoholic beverages is aimed. Analogous sampling strategies involving gas diffusion or dialysis have been already proposed for in-vivo sampling for pharmacological studies (Lange at al. 2000), insitu sampling for bioprocess monitoring (Torto et al. 1999) or in field monitoring of methane in environmental studies (Rothfuss et al. 1996). As the probe is immersed into the aqueous sample for direct sampling, the sample injection process is not required and the number of analytical channels is lessened, leading to an automated procedure less susceptible to the operator interferences.

\section{EXPERIMENTAL}

The reagent / acceptor stream was a $0.3 \mathrm{~mol} \mathrm{l}^{-1}$ $\mathrm{K}_{2} \mathrm{Cr}_{2} \mathrm{O}_{7}$ plus $4.0 \mathrm{~mol}^{-1} \mathrm{H}_{2} \mathrm{SO}_{4}$ solution. Working standards $(0.0-50.0 \% \mathrm{v} / \mathrm{v}$ ethanol $)$ were prepared from $96 \% \mathrm{v} / \mathrm{v}$ ethanol, after applying correction to $100 \% \mathrm{v} / \mathrm{v}$.

Red wines and distilled spirits (vodka, whiskey, cognac and "cachaça" - a Brazilian spirit) were purchased in a local store and analyzed without any prior treatment.

The flow setup (Fig. 1) comprised a model IPC 4 Ismatec peristaltic pump, a model 432 Femto spectrophotometer equipped with a model QS1.000 Hellma flow cell (10-mm optical path, 120- $\mu$ l inner volume) and connected to a model $111 \mathrm{Kipp}$ \& Zonen strip-chart recorder. The manifold was built-up with $0.5 \mathrm{~mm}$ i.d. polyethylene tubing. A PTFE tubular membrane (1.0 mm i.d., 50\% porosity, $0.8 \mu \mathrm{m}$ pore size) supplied by Nishitani \& Co., Osaka, Japan, was used for manufacturing the sampling probe. It was coupled to the flow system by connecting its ends to the polyethylene tube 


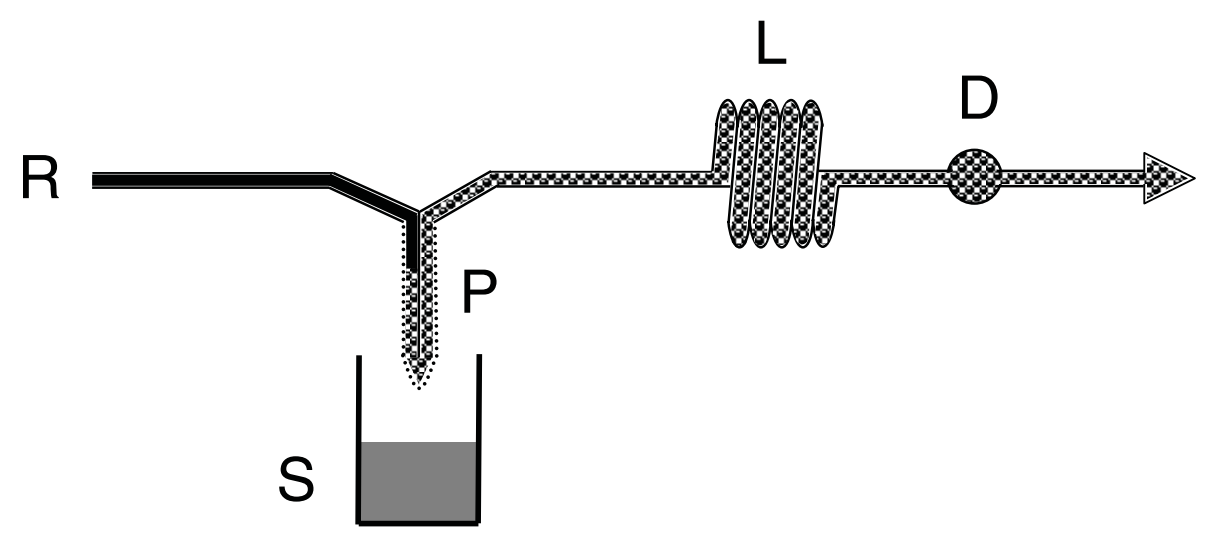

Fig. 1 - Flow diagram. $\mathrm{R}=$ reagent; $\mathrm{S}=$ sample; $\mathrm{P}=$ probe; $\mathrm{B}=$ transmission line; $\mathrm{D}=$ detector. For details and system operation, see text.

(Fig. 2). The PTFE tubing was bended towards a "U" shape.

The analytical cycle started by immersing the probe into the sample (Fig. 1), that acted as the donor solution. The acidic $\mathrm{Cr}(\mathrm{VI})$ acceptor / reagent stream that was continuously pumped through the probe collected the diffused ethanol. $\mathrm{Cr}(\mathrm{VI})$ was then reduced by ethanol and the formed $\mathrm{Cr}$ (III) was spectrophotometrically monitored at $600 \mathrm{~nm}(\mathrm{Ca}-$ puti et al. 1968).

The analytical procedure consisted only in successively dipping the sampling probe into the sample or standard solution and comparing the detector responses. No prior sample treatment was needed. After system dimensioning, the main figure of merits were evaluated. Comparing the results with those obtained with a recommended procedure involving sample distillation and specific mass measurement (Cunniff 1995) assessed the accuracy.

\section{RESULTS AND DISCUSSION}

The proposed sampling strategy is simple and rugged, yielding precise measurements. Aspects related to the involved reactions, probe behavior, and application of the proposed strategy, were then properly evaluated. The efficiency of gas transfer was always reproducible, being evaluated by adding a known analyte amount to the receptor solution
(Torto et al. 1999).

Regarding reagent optimization, increasing the $\mathrm{K}_{2} \mathrm{Cr}_{2} \mathrm{O}_{7}$ concentration enhanced sensitivity, but no further improvement was noted beyond $0.3 \mathrm{moll}^{-1}$. This value was selected by taking also into account that any further increase in the dichromate concentration would increase the baseline absorbance with a consequent lessening in the signal-to-noise ratio and increase in the waste generation. Acidity plays also a relevant role in system design, and analytical signal was not recorded for $<1.0 \mathrm{~mol} \mathrm{l}^{-1} \mathrm{H}_{2} \mathrm{SO}_{4}$. Above this threshold, increasing acidity improved sensitivity, highest analytical signals being verified for the highest tested level, $6.0 \mathrm{~mol}^{-1} \mathrm{H}_{2} \mathrm{SO}_{4}$. The acidity however could not be increased at will in order to avoid excessive increase in viscosity thus hydrodynamic impedance. Moreover, it was verified that lifetime of the pumping tube (Tygon) was reduced to only about one week when acidity was $6.0 \mathrm{~mol} \mathrm{l}^{-1} \mathrm{H}_{2} \mathrm{SO}_{4}$. The above-mentioned effects may cause leakage. Acidity was then set as $4.0 \mathrm{~mol}$ $1^{-1} \mathrm{H}_{2} \mathrm{SO}_{4}$. It should be stressed that the flow-cell outlet solution is directed towards a waste disposal flask for further treatment.

The mean available time for reaction development is proportional to the length of the analytical path (Ruzicka and Hansen 1988); however increasing this length from 20 to $100 \mathrm{~cm}$ did not promote a significant signal enhancement, emphasizing that 

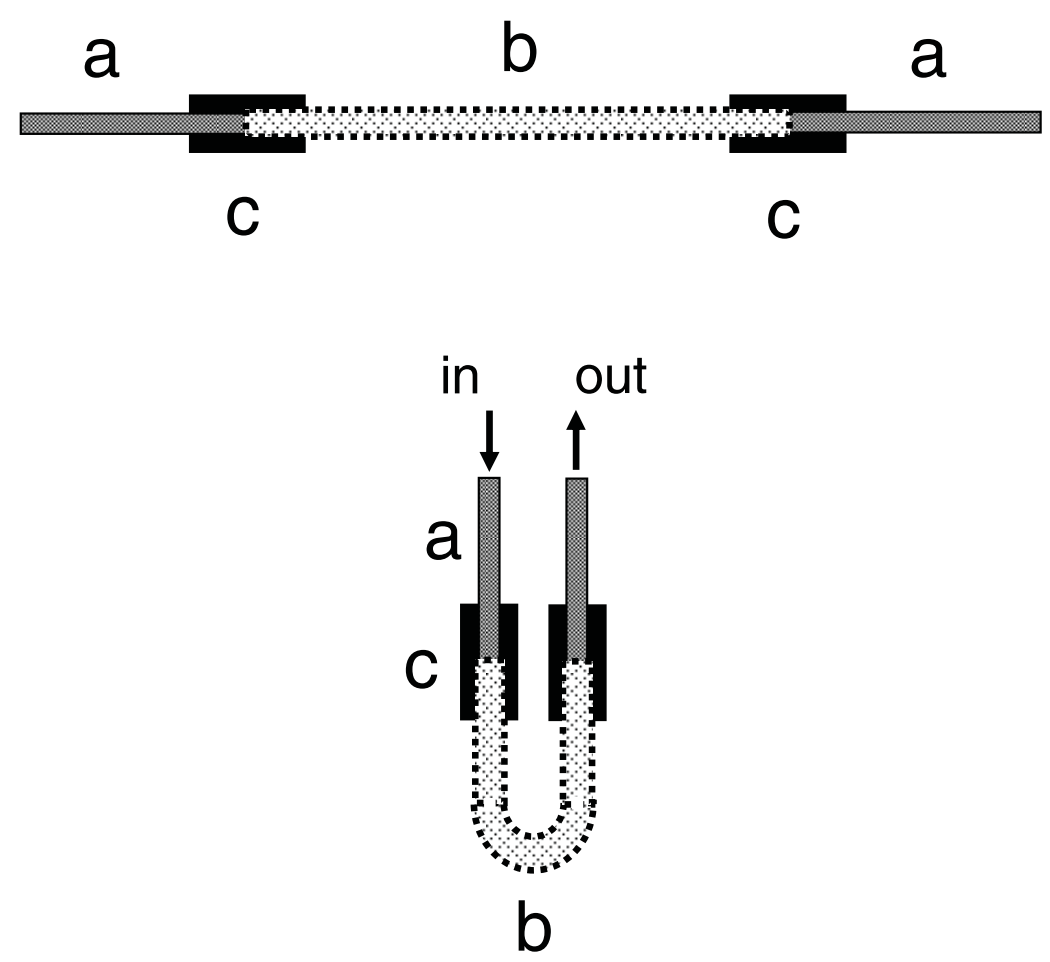

Fig. 2 - The sampling probe. The polyethylene (a) and PTFE (b) tubes are attached to each other by means of Tygon (c) tubular connectors (upper), and bended towards the probe shape (lower).

reaction completeness was attained. The transmission line between probe and detector was then kept as short as possible $(20 \mathrm{~cm})$. Good mixing conditions were attained, as a thin baseline ( $\Delta$ absorbance $<0.001$ ) was always recorded.

In classical FIA systems exploiting gas diffusion, the contact time of donor and acceptor streams with the membrane is controlled by the flow rate of both solutions and by the geometry of the phase separating device. In general, the efficiency of mass transport is higher for lower flow rates (Fang 1993). When sensitivity is critical and the sample volume is not limiting, the acceptor stream can flow slower than the donor stream (or even be stopped), while the donor stream with the sample in an "infinite volume" situation (Krug et al. 1981) flows through the diffusion cell. Higher analyte transference is then attained. The proposed sampling strategy is analogous to this situation, as the sample (donor solution) is kept in a container and present in a much larger volume in relation to the acceptor stream. The mean available time for analyte transference to the acceptor solution is then ruled by its flow rate. Consequently, the lower the acceptor stream flow rate, the higher the analytical signal (Fig. 3). However, this flow rate cannot be decreased indefinitely in order to avoid a pronounced lessening in sample throughput. The acceptor stream flow rate was then fixed as 1.0 $\mathrm{ml} \mathrm{min}{ }^{-1}$, meaning a sampling rate of $30 \mathrm{~h}^{-1}$.

Differences in donor and acceptor stream temperatures played also a relevant role in the system design, especially within $0-20^{\circ} \mathrm{C}$ range. This was confirmed by placing the sample container inside a thermostatic water bath $\left(5-60^{\circ} \mathrm{C}\right)$ and maintaining the temperature of the acceptor stream as $25 \pm 1^{\circ} \mathrm{C}$ through air conditioning facilities. The effect refers to the increased ethanol volatility under higher temperatures. Beyond $20^{\circ} \mathrm{C}$, influence of this tem- 


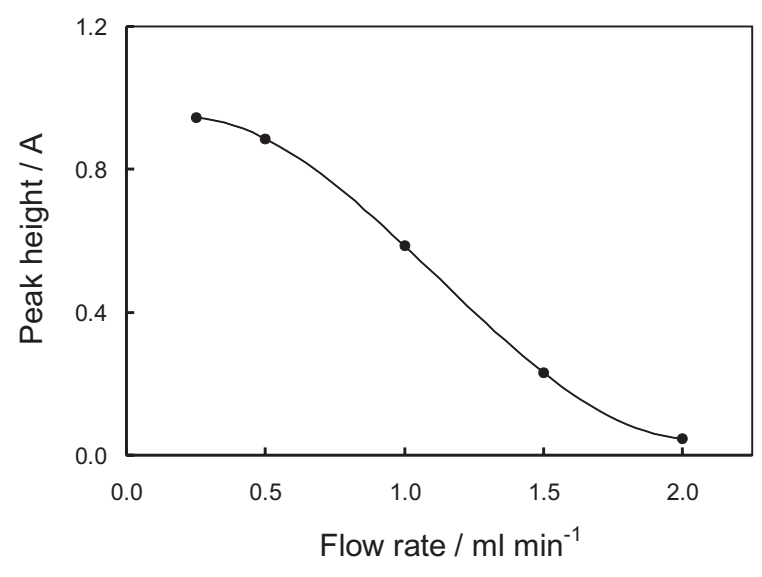

Fig. 3 - Influence of acceptor stream flow rate. Figure refers to $50.0 \%(\mathrm{v} / \mathrm{v})$ ethanol.

perature difference was less pronounced. In fact, a $10 \%$ increase in the slope of the analytical curve was noted when the sample temperature was raised from 20 to $60^{\circ} \mathrm{C}$. For routine analyses, this aspect is not really a drawback, since all the samples present a similar temperature, dictated by the controlled environment of the laboratory.

The sampling depth should also be taken into consideration (Kuban 1992), and its influence was investigated within $2-50 \mathrm{~cm}$ by placing the sample in a cylindrical flask $(\mathrm{d}=5 \mathrm{~cm} ; \mathrm{h}=50 \mathrm{~cm})$ and sampling at different depths. For deeper sampling, increased vapor solubility in the non-porous membrane is observed, and surface influence becomes less relevant, leading to an enhancement of the diffusion efficiency. An opposite effect is observed with porous membranes, and this was confirmed here for the PTFE membrane. As the analytical signal was dependent on the sampling depth, the probe was always immersed at the same depth $(5 \mathrm{~cm})$.

Length of the tubular membrane also influenced the diffused ethanol amount, as demonstrated in experiments involving three different probes $(5$, 10 and $15 \mathrm{~cm}$ ). For larger probes, both the available area and the mean residence time of the reagent inside the probe are increased, increasing the transferred analyte amount. For practical purposes, and considering that sensitivity was not the issue, the probe length was selected as $5 \mathrm{~cm}$.
The analytical signal was little affected $(<1 \%)$ when the sample was stirred. This is an advantageous feature regarding in-situ analyses where sudden variations in sample stillness are expected.

Under the above conditions, the ethanol diffusion efficiency was estimated as $2.5 \%$. In the proposed application this is a beneficial feature, as the analyte is found at higher concentrations in the assayed samples. In this way, the cumbersome dilution step, inherent to most of the flow-based procedures applied to similar matrices (Fernandez and Reis 2004), is avoided.

Presence of other alcohols and aldehydes in their usual $\mathrm{mg} \mathrm{l}^{-1}$ concentration levels causes negligible interferences ( $<1 \%$ for $2.0 \% \mathrm{v} / \mathrm{v}$ ethanol). Sulfite ions and colored compounds do not interfere in view of the hydrophobic characteristic of the membrane. Care should be taken regarding sample exchange, and immersing the probe in water between successive measurements is a guarantee for reproducible conditioning. Long-term reproducibility of results was not observed, $>20 \%$ variations in analytical signals being noted after assaying a typical sample in different days. It is therefore advisable to always calibrate the system before analysis.

The analytical curve is linear up to $50 \%(\mathrm{v} / \mathrm{v})$ ethanol $(\mathrm{r}>0.998 ; \mathrm{n}=8)$, and baseline drift is $<0.005$ absorbance for a 4 -h operation period. The system handles 30 samples per hour, meaning $0.6 \mathrm{mmol}$ potassium dichromate consumed per determination. Results are precise (r.s.d. $<2 \%$ ) and in agreement with those obtained by the official procedure. After applying the statistical $t$-test to data in Table I, no significant differences were observed at the $95 \%$ confidence level.

\section{CONCLUSIONS}

A tubular gas membrane acting as a probe in flow analysis is a feasible strategy for non-invasive sampling. System design is simplified and the separation step is accomplished in line. Matrix interferences are lessened, this aspect becoming especially 
TABLE I

Comparative results. Ethanol contents in $\% \mathrm{v} / \mathrm{v}$ as determined by the proposed and by the official (Cunniff 1995) procedures. Mean values and uncertainties based on three replications. Samples 1 to 7 = distilled spirits; samples 8 to $17=$ red wines.

\begin{tabular}{|c|c|c|}
\hline Sample & Official & Proposed \\
\hline 01 & $39.1 \pm 0.1$ & $39.3 \pm 1.4$ \\
\hline 02 & $39.4 \pm 0.0$ & $39.8 \pm 0.7$ \\
\hline 03 & $38.7 \pm 0.1$ & $38.3 \pm 0.5$ \\
\hline 04 & $39.2 \pm 0.6$ & $38.6 \pm 0.6$ \\
\hline 05 & $37.2 \pm 0.2$ & $36.5 \pm 1.1$ \\
\hline 06 & $37.2 \pm 0.1$ & $36.6 \pm 0.2$ \\
\hline 07 & $37.7 \pm 0.2$ & $36.7 \pm 0.5$ \\
\hline 08 & $10.8 \pm 0.1$ & $10.7 \pm 0.2$ \\
\hline 09 & $11.4 \pm 0.2$ & $11.3 \pm 0.1$ \\
\hline 10 & $11.9 \pm 0.2$ & $11.8 \pm 0.1$ \\
\hline 11 & $11.9 \pm 0.1$ & $11.8 \pm 0.1$ \\
\hline 12 & $11.8 \pm 0.1$ & $11.9 \pm 0.2$ \\
\hline 13 & $11.7 \pm 0.2$ & $11.8 \pm 0.1$ \\
\hline 14 & $12.7 \pm 0.2$ & $12.6 \pm 0.1$ \\
\hline 15 & $12.1 \pm 0.2$ & $11.9 \pm 0.1$ \\
\hline 16 & $12.8 \pm 0.2$ & $12.7 \pm 0.1$ \\
\hline 17 & $12.6 \pm 0.1$ & $12.7 \pm 0.2$ \\
\hline
\end{tabular}

attractive in dealing with red wine analysis.

The proposed system is rugged, and the membrane material proved to be resistant and stable during the entire development of this work. If necessary, membrane replacement is easily performed; therefore a skilled analyst is not needed. Further research aims to investigate in detail the membrane lifetime in relation to applications outside the laboratory environment and / or involving a process control analyzer.

As partial and reproducible separation is inherent to the proposed procedure, the dynamical range of the system can be modified by altering some of the involved parameters such as e.g. flow rate or even by stopping the acceptor stream inside the sampling probe for a pre-established time period. Research focusing on this matter is presently in progress.

\section{ACKNOWLEDGMENTS}

The authors thank partial support received from Fundação de Amparo à Pesquisa do Estado de São Paulo (FAPESP) (proc. 04/02805-7), Conselho Nacional de Desenvolvimento Científico e Tecnológico (CNPq) and Gabinete de Relações Internacionais da Ciência e do Ensino Superior (Portugal).

\section{RESUMO}

Uma membrana tubular de PTFE permeável a espécies gasosas foi empregada como sonda em sistemas de análises em fluxo visando a proposta de uma estratégia de amostragem não invasiva. Como aplicação, foi selecionada a determinação espectrofotométrica de etanol em bebidas alcoólicas. A sonda é imersa na amostra, permitindo que o analito se difunda através desta e seja coletado pelo fluxo aceptor (solução ácida de dicromato), levando à formação de $\mathrm{Cr}$ (III), o qual é monitorado a $600 \mathrm{~nm}$. Linearidade da curva analítica é verificada até $50,0 \%(\mathrm{v} / \mathrm{v})$ de etanol $(\mathrm{r}>0,998 ; \mathrm{n}=8)$, derivas de linha base são menores do que 0,005 absorbância durante períodos de 4 horas de operação e a velocidade analítica é de $30 \mathrm{~h}^{-1}$ o que corresponde a $0.6 \mathrm{mmol} \mathrm{K}_{2} \mathrm{Cr}_{2} \mathrm{O}_{7}$ por determinação. Os resultados são precisos (d.p.r. $<2 \%$ ) e concordantes com aqueles obtidos por um método oficial.

Palavras-chave: análises por injeção em fluxo, determinação de etanol, difusão gasosa, membrana semi-permeável, espectrofotometria no UV-vis.

\section{REFERENCES}

Callul M, Lopez E, Marcé RM, Olucha JC And BORRULL F. 1992. Determination of carboxylic acids, sugars, glycerol and ethanol in wine and grape must by ion-exchange high-performance liquid chromatography with refractive index detection. J Cromatogr A 590: 215-222.

Caputi AJR, Ueda M And Brown T. 1968. Spectrophotometric determination of ethanol in wine. Am J Enol Vitic 19: 160-164.

CUNNIFF P (Ed). 1995. Official methods of analysis of AOAC Int, Vol II, $16^{\text {th }}$ ed., Arlington: AOAC Int, ch $28,1 \mathrm{p}$. 
FANG Z. 1993. Flow injection separation and preconcentration. Weinheim: VCH, 259 p.

Fernandez EN AND Reis BF. 2004. Automatic procedure for the determination of ethanol in wine exploiting multicommutation and enzymatic reaction with detection by chemiluminescence. J AOAC Int 87: 920-926.

HARTRIDGe H And Roughton FJW. 1923. A method of measuring the velocity of very rapid chemical reactions. Proc Roy Soc A 104: 376-394.

JACQUES KA, LyONS TP AND KEKSALL DR. 2003. The alcohol textbook, $4^{\text {th }}$ ed., Nottingham: Nottingham University Press, 686 p.

Krug FJ, Mortatti J, Pessenda lCR, Zagatto EAG AND BERGAMIN $\mathrm{F}^{\mathrm{O}}$ H. 1981. Flow injection spectrophotometric determination of boron in plant material with Azomethine-H. Anal Chim Acta 125: 29-35.

KubAN V. 1992. Gas diffusion/permeation flow injection analysis. Part 1. Principles and instrumentation. Crit Rev Anal Chem 23: 323-354.

LANGe ECM, Boer AG ANd BReIMER DD. 2000. Methodological issues in microdialysis sampling for pharmacokinetic studies. Adv Drug Deliv Rev 45: 125-148.

Mattos IL, Sartini RP, Zagatto EAG, Reis BF AND GINE MF. 1998. Spectrophotometric flow injection determination of ethanol in distilled spirits and wines involving permeation through a silicon tubular membrane. Anal Sci 14: 1005-1008.

Miro M And Frenzel W. 2004. Automated membrane-based sampling and sample preparation exploiting flow-injection analysis. Trends Anal Chem 23: 624-636.

Rothfuss F, Bijnen FGC, Conrad R, Harren FJM AND REUSS J. 1996. Combination of photoacoustic detector with gas diffusion probes for the measurement of methane concentration gradients in submerged paddy soils. Chemosphere 33: 24872504.
RuZiCKA J AND HANSEN EH. 1975. Flow Injection Analyses. Part I. A new concept of fast continuous flow analysis, Anal Chim Acta 78: 145-157.

RUZICKA J AND HANSEN EH. 1988. Flow injection analysis, $2^{\text {nd }}$ ed., J Wiley \& Sons, New York, USA, Interscience, $499 \mathrm{p}$.

SCHMID RD (Ed). 1991. Flow injection analysis (FIA) based on enzymes or antibodies, Weinheim: $\mathrm{VCH}$ Pub, 335 p.

SkEGGS JR LT. 1957. Automatic method for colorimetric analysis. Am J Clin Pathol 28: 311-322.

Smith JP And Hinson-Smith V. 2002. Flow injection analysis: quietly pushing ahead. Anal Chem 74: 385A-388A.

Torto N, Laurell T, Gorton L AND MARKoVARGA G. 1999. Recent trends in application of microdialysis in bioprocess. Anal Chim Acta 379: 281-305.

Trojanowicz M. 2000. Flow injection analysis. Instrumentation and applications, Singapore: World Scientific Publishing Co., 479 p.

UKEDA H. 2004. FIA Bibliography (42). J Flow Injection Anal 21: 159-166.

Zagatto EAG AND Worsfold PJ. 2005. Flow analysis: overview. In: WORSFOLD PJ, TOWNSHEND A AND POOLE CF (Eds), Encyclopedia analytical science, $2^{\text {nd }}$ ed., Oxford: Elsevier 3: 24-31.

Zagatto EAG, Reis BF, Bergamin $\mathrm{F}^{\mathrm{O}} \mathrm{H}$ AND KRUG FJ. 1979. Isothermal distillation in flow injection analysis. Determination of total nitrogen in plant material. Anal Chim Acta 109: 45-54. 